\title{
Case Report: Duchenne Muscular Dystrophy in a 6-Year-Old Boy
}

\author{
Christin Natalia Kalembang ${ }^{1}$, I Gusti Ngurah Made Suwarba ${ }^{1}$, Dewi Sutriani Mahalini ${ }^{1}$, \\ Herman Saputra ${ }^{2}$
}

${ }^{1}$ Department of Child Health, Medical Faculty, Udayana University, Sanglah Hospital, Denpasar, Bali, Indonesia

${ }^{2}$ Department of Anatomy Pathology, Medical Faculty, Udayana University, Sanglah Hospital, Bali, Indonesia

\section{Email address:}

christinkalembang@gmail.com (C. N. Kalembang), suwarbangurah@yahoo.co.id (I. G. N. M. Suwarba),

dewi_sutriani@yahoo.com (D. S. Mahalini), herman_saputradps@yahoo.com (H. Saputra)

\section{To cite this article:}

Christin Natalia Kalembang, I Gusti Ngurah Made Suwarba, Dewi Sutriani Mahalini, Herman Saputra. Case Report: Duchenne Muscular Dystrophy in a 6-Year-Old Boy. Clinical Neurology and Neuroscience. Vol. 5, No. 3, 2021, pp. 41-45.

doi: $10.11648 /$ j.cnn.20210503.11

Received: May 3, 2021; Accepted: June 19, 2021; Published: June 25, 2021

\begin{abstract}
Duchenne Muscular Dystrophy (DMD) is an X-link reccessive disorder, caused by mutation in dystrophin gene. Therefore body is incapable to synthesize dystrophin, the protein needed for muscle contraction. The incidence of DMD 1: 4000 male with age 3 to 5 years. Furthermore the patient will experience functional decline, loss of ambulation and early death due to cardiac or respiratory failure. Patient will be unable to walk at the beginning of second decade and usually decease at the age of 20s. Hereby we reported a male, 6-years-old presented with weakness on both of his legs. Patient had history of recurrent falls while walking and difficulty to climb stairs since 3-years-old. Patient also had difficulty to stand up immediately from sitting position. He had to grab his feet in order to make climb movement before stand up. Physical examination showed pseudo hypertrophy of calf muscle and positive Gower Maneuver. Laboratory examination showed creatinin kinase 16.891 (about 113 times higher than normal value). EMG revealed lesion of the muscle. Biopsy was taken from left muscle gastrocnemius and showed variability of muscle size without regeneration and fibrosis. The result of genetic test showed deletion of Dp427c and exon 1-2 of dystrophin gen. After been treated with corticosteroid for a year, the patient showed improvement in his gait moreover the weakness on both of his legs has became lessen. We emphasized the importance of early and accurate diagnosis of DMD for better quality of life.
\end{abstract}

Keywords: Duchenne Muscular Dystrophy, X-linked Neuromuscular Disorders, Distrofin, Muscle Degeneration, Muscle Weakness

\section{Introduction}

Duchenne Muscular Dystrophy (DMD) is an atypical inherited musculoskeletal disorder characterized by progressive muscular weakness in early stage and pathologic features of fibrosis with fatty replacement, particularly in late stage [1]. Incidence of DMD 1: 4000 male with age 3 to 5 years. Gene size is relatively large with 79 exons, located on Xp 21 [1-4]. In 1884, for the first time Wilhelm Heinrich Erb used the term dystrophia muscularis progressiva to define the classic description of pseudohypertrophy in his patients, showing atrophy in upper part of the body but not having a family relationship. In 1855, Duchenne gave a more complete description of atrophy in his patients. progressive muscular disease in children. Steinberg et al explained that the abnormalities of dystrophin protein were the main cause of DMD [5].

Patients appear normal at birth then showed clumsiness at the age 3 to 5 years. Furthermore the signs of DMD can be noticed obviously, especially the four classical DMD motor signs such as gower maneuver, waddling gait (myopathic gait), toe walking and stair climbing. Heart abnormalities are frequently found after the age of 10 years old. [1, 3, 4]

Clinical features in DMD are increased plasma creatinine kinase, the plasma creatinine kinase generally surpass 1,000 $\mathrm{IU} / \mathrm{L}$ and can reach up to $30,000 \mathrm{IU} / \mathrm{L}$. Electromyography may help to distinguish myopathic process from 
neurogenenic process. In addition muscle biopsy is performed in patients without detectable etiology. Nowadays molecular genetic test has switched the role of muscle biopsy in many diagnostic centres [6].

\section{Case}

A 6-years-old boy presented to our Pediatric outpatient clinic with chief complain weakness on both of his legs and hands. Patient had history of recurrent falls while walking and difficulty to climb stairs since 3 years old. Patient also had difficulty to stand up immediately from sitting position. He had to grab his feet before stand up.

Patients was born aterm, spontaneously helped by doctor with birth weight 2900 gram from non-consaguineous marriage. He appeared normal at birth, he was able to stand up on his own and walk when he was 16-month-old without crawling first. Patient was the second child (figure 1), none of the family have the same complaint like him. The patient was well nourished.

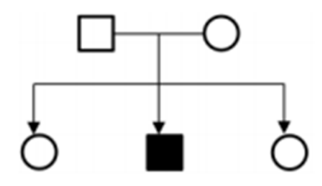

Figure 1. Pedigree of the patient which showed patient was the $2^{\text {nd }}$ child from 3 siblings.

Physical examination showed normal vital sign except pseudohypertrophy on both of his legs. Gower Maneuver was also positive (Figure 2). Complete blood count found no abnormality, hemoglobin $(13,6 \mathrm{~g} / \mathrm{dL})$, hematocrit $(39,7 \%)$, white blood cell $\left(8,1 \times 10^{\wedge} 3 / \mu \mathrm{L}\right)$, platelet $\left(310 \times 10^{\wedge} 3 / \mu \mathrm{L}\right)$. There was an increased in creatinin kinase $(16,891 \mathrm{U} / \mathrm{L})$ about 113 fold times higher than normal. This value suggesting the suspicion of progressive muscular dystrophy. The patient then underwent electromyography (EMG). The EMG found normal nerve rate of nervus medianus sinistra, nervus ulnaris sinistra, nervus peroneus sinistra, nervus tibialis sinistra, and nervus suralis sinistra however there was decreased in amplitude of nervus ulnaris sinistra, nervus peroneus sinistra, and nervus suralis sinistra. The needle of EMG on musculus gastrocnemius and caput medialis sinistra showed PSW +4 , fibrillation +4 , MUAP: early recruitment, polyphasic, low amplitude, shorten duration. These finding concluded that the lesion was on the muscle (Figure 3). Thus biopsy was performed from left muscle gastrocnemius and showed variability of muscle size without regeneration and fibrosis, which can be part of muscular dystrophy (Figure 4).

However, these finding didn't specific for muscular dystrophy thus genetic testing were performed. The result of genetic test showed deletion of Dp427c and exon 1-2 on dystrophin gen. Deletion in exon 1 may not cause the formation of mRNA so that no dystrophin protein is formed. This deletion is predicted to produce clinical manifestation of DMD.

Finally the patient was treated with prednison for a year with dosage $0.75 \mathrm{mg} / \mathrm{kg} /$ day. In addition calcium syrup $10 \mathrm{ml}$ and vitamin D 400 IU were also given every day to prevent the side effects of prednisone and monitoring weight gain as well as signs of cushing syndrome. Currently the patient showed improvement of his gait and the weakness on both of his legs had became lessen.

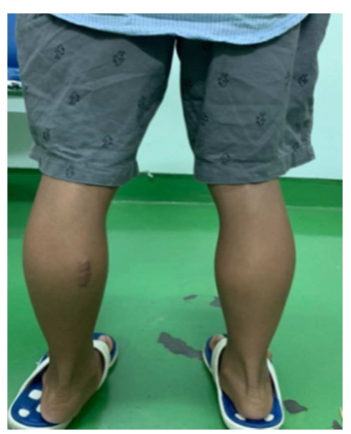

Figure 2. Clinical picture of the patient showed pseudohypertrophy of calf muscle.

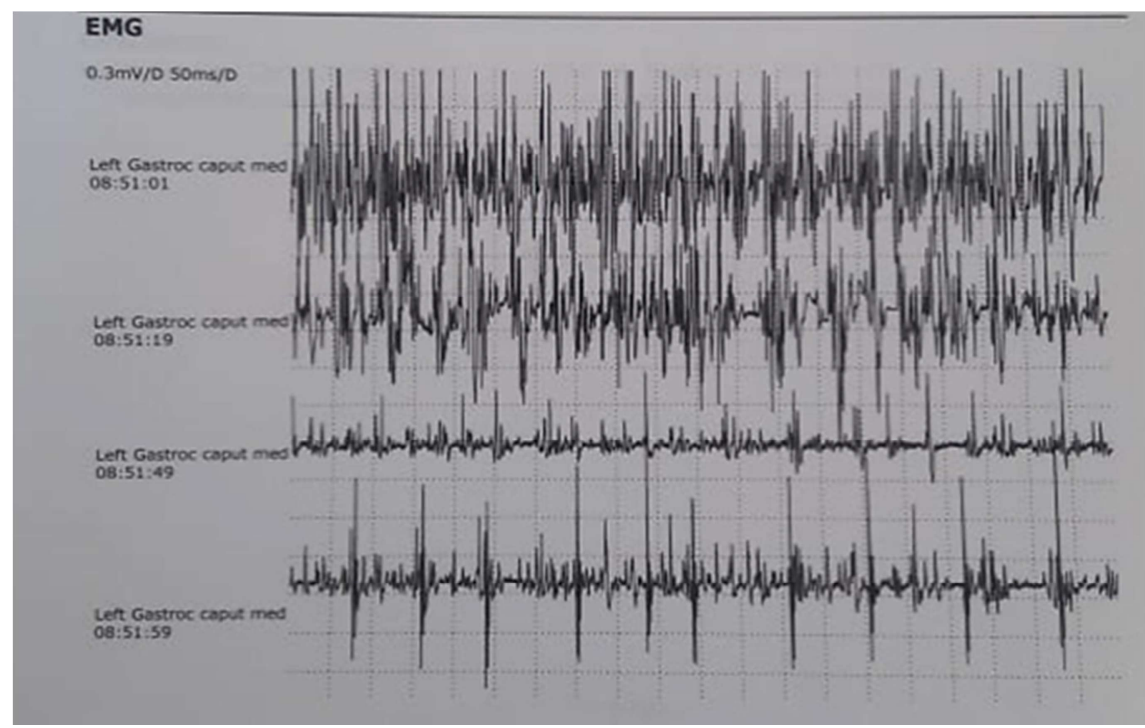

Figure 3. The Electromyography (EMG) of musculus gastrocnemius. 


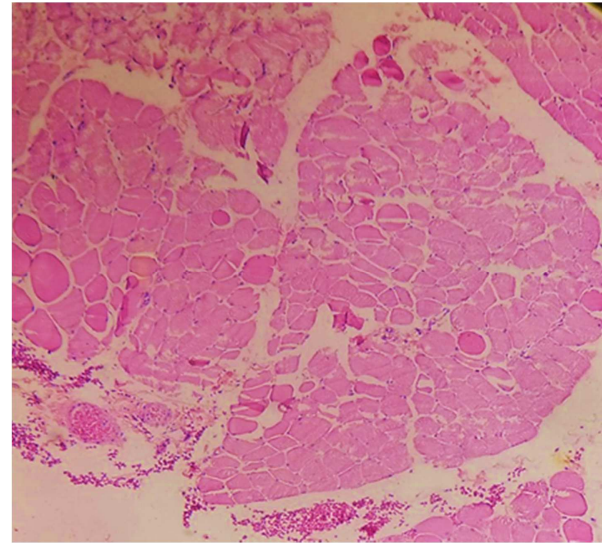

Figure 4. The biopsy picture of musculus gastrocnemius sinistra showed necrotic part of the muscle with 100x magnitude.

\section{Discussion}

Duchenne Muscular Dystrophy is an X-linked recessive disorder leading to mutation and delesion of dystrophin gene, thus the body is unable to synthesize dystrophin, protein needed for muscle contraction. The incidence of DMD is 1 : 4000 male with age 3 to 5 years. Gene size is relatively large with 79 exons and located at Xp 21. Each time the muscle contract, muscle damage occurs which is repaired but with insufficient protein producing fixed muscle which is also damaged. The continuous damage, repair and supplanting of muscle with fibro fatty tissue is responsible for the clinical progressive muscle wasting and degeneration that generally occurs in age 3-4 years [1, 3].

Dystrophin comprises of an N-terminal actin-binding domain, 24 spectrin-like repeat units interspersed by four hinge regions, followed by cysteine-rich domain and C-terminal domain. The cysteine-rich domain binds to laminin-2 through alpha and beta-dystroglycan, acts as mechanical link between actin in cytoskeleton and extracellular matrix. The DMD gene contains 79 exons but accounts for only $0.6 \%$ of the gene, the rest made of large introns. The large size of DMD gene makes it susceptible to mutations, leading to malfunction of dystrophin, resulting in premature truncated and unstable dystrophin protein [5]. The majority of mutations are intragenic deletions, which accounted for $65-72 \%$ cases. The absence of dystrophin in cardiac muscle increases intracellular calcium levels, leading to activation of calpains, myocardial cell degeneration or apoptosis and fibrosis. Excessive fibrosis induces cardiomyopathy then activate renin-angiotensin system and releases angiotensin II (AT II) thus increases the transforming growth factor- $\beta$ (TGF- $\beta$ ) expressions (particularly TGF- $\beta 1$ ) through the activation of angiotensin receptor type 1 in cardiac myocytes and fibroblasts. TGF- $\beta$ induces cardiac fibroblast proliferation, deposition of extracellular matrix protein and development of cardiomyocyte hypertrophy. In the brain, the absence of dystrophin results in disruption of synapse integrity and interneuron transmission $[1,7]$.

The progression of muscle weakness in DMD follows stereotypic pattern through 5 stages consist of several stages as follow: $[7,8]$

(1) Presymptomatic phase (Birth - 2 years): patient usually clinically asymptomatic at birth until the age of two years parents report delayed of motor mile stones (standing and walking), the mean age for walking in boys with DMD is 18 months (12-24 months).

(2) Early ambulatory phase (2 - 6 years): patient complains recurrent falls while walking and calf enlargement and noticeable Gower sign, the difficulty in arising from supine position and squatting position (Figure 4). The weakness can be noticed between the age of 2 to 4 years, with difficulty in running, jumping, standing from sitting, squatting and climbing upstairs. The mean age at diagnosis in boys with negative family history is 4 years.

(3) Late ambulatory phase (6-11 years): progressive weakness of muscle; and difficulty in rising from supine position. Contractures of tendo achillis, tensor facia lata and hamstrings can further compromise mobility. At the age of 10 years old, boys with DMD will need long leg braces for ambulation; and by the age of 11-13 years old, will begin to lose ambulation and get confined to wheelchairs. The speed of loss functions vary among children with DMD.

(4) Early non-ambulatory (10-15 years) loss of ambulation, muscle weakness and atrophy progress rapidly, leading to limitation in movement and contracture of lower limbs, followed by upper limbs. Scoliosis and respiratory muscle weakness compromise breathing, pulmonary function tests show gradual decline in forced vital capacity and total lung capacity.

(5) Late non-ambulatory ( $>15$ years): severe upper limb weakness, lower limb contractures, respiratory weakness, loss of coughing abilities, kyphoscoliosis and cardiomyopathy.

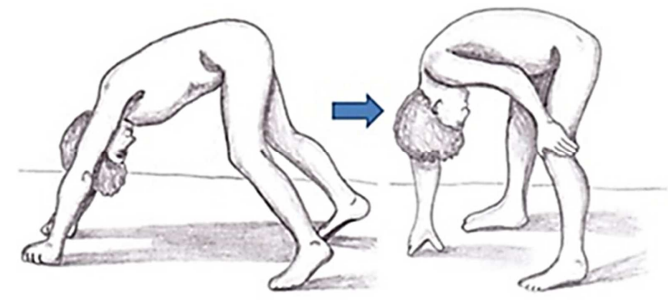

Figure 5. Clinical sign of Gower sign.

In this case, the patient's development was said normal at birth and showed delay of motor development at the age of 3 years. He was complained had difficulty in walking, climbing stairs accompanied with muscle weakness and positive Gower sign.

Diagnosis was confirmed by high levels of $\mathrm{CK}$, muscle biopsy, electromyography and genetic analysis. Clinical features and increased plasma creatinine kinase are crucial in establishing the diagnosis [7]. The increased permeability of sarcolemma damaged due to repeated contractions in DMD patients leads to leakage of proteins, such as CK into the plasma resulting in elevated levels of $\mathrm{CK}$ in the serum $[1,6]$. Muscle biopsy is crucial for diagnosis and evaluation of 
patients whom presented acute or progressive weakness or whom is suspected of having neuromuscular disorder. It can establish etiology or focuses the differential diagnosis [1, 8 -10]. The frequent chosen muscles for biopsy include the deltoid, biceps and quadriceps since it have sufficient fiber type percentages and muscle fiber. The gastrocnemius and tibialis anterior muscles are appropriate choices in diseases with distal limb signs and symptoms. The abnormal histopathology finding in DMD such as, myopathic pattern with breaks of sarcolemma, necrosis myophagocytosis, reduced or absent dystrophin seen around the sarcolemma membrane size for comparison and reduction in molecular size and quantity of dystrophin. Nowadays molecular genetic testing has replaced the role of muscle biopsy in many centres [6]. Genetic testing is usually the first confirmatory test since approximately $70 \%$ of individuals with DMD have single-exon or multi-exon deletion or duplication of dystrophin gene, dystrophin gene deletion (Figure 6) [9] However muscle biopsy is indicated in patients without detectable mutation [7-10].

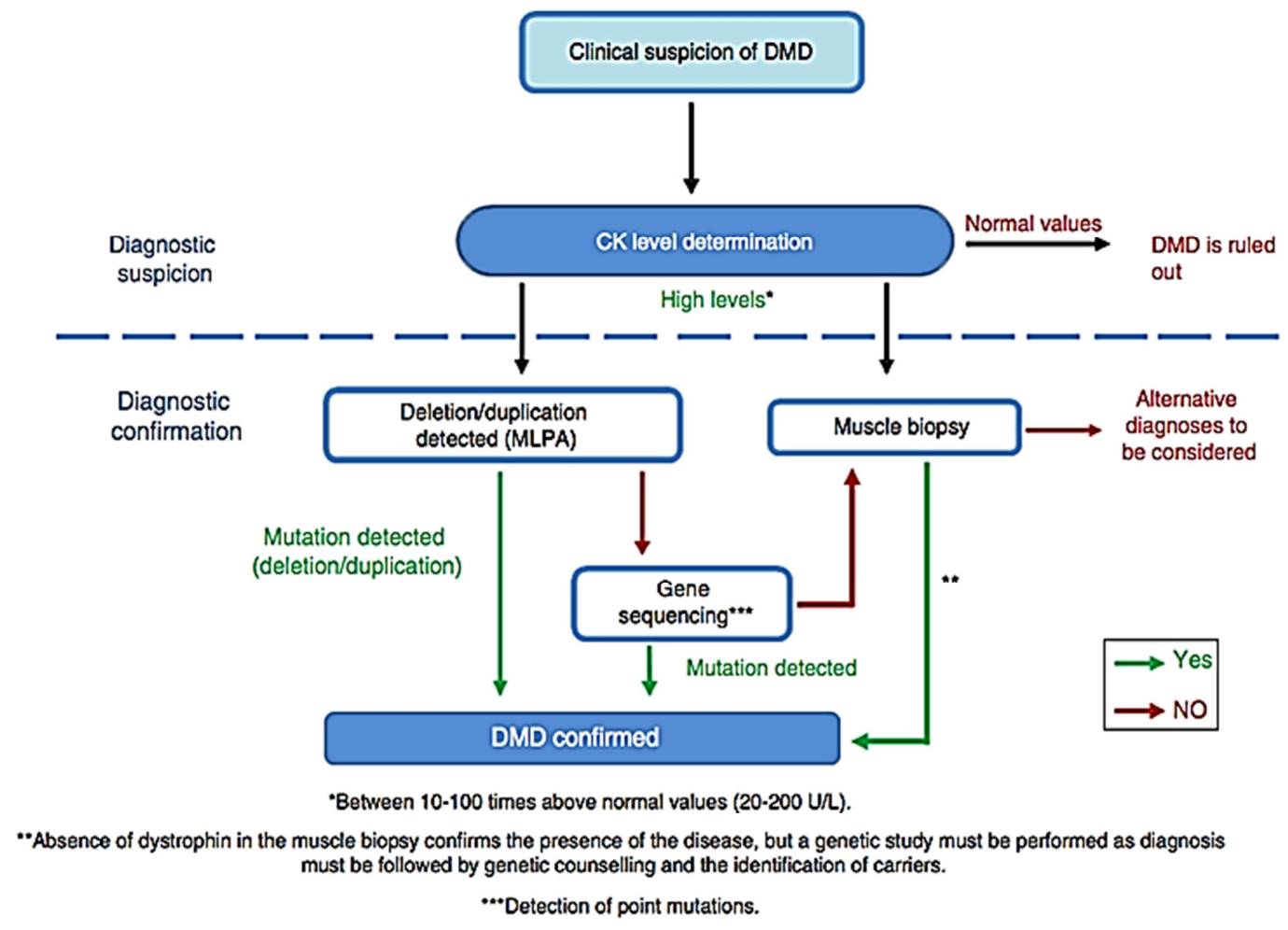

Figure 6. Diagnostic algorithm for DMD, from suspicion to confirmation [5].

In this case, laboratory examination showed increase of creatinin kinase $(16,891 \mathrm{U} / \mathrm{L})$ about 113 fold from normal value suggesting the suspicion of progressive muscular dystrophy. The EMG showed there was lesion on the muscle. Biopsy taken from left musculus gastrocnemius showed variability of muscle size without regeneration and fibrosis. Genetic testing showed deletion on Dp427c and exon 1-2 of dystrophin gen.

Corticosteroids are the standard treatment with mechanisms of action including: (1) reduce muscle necrosis and inflammation; (2) modulate cell response to inflammation; (3) increase muscle regeneration and growth due to anabolic effects; (4) reduce the rate of muscle breakdown; (5) act as direct transcriptional modifier to increase dystrophin expression in muscle fiber; and (6) increase synergistic molecules [1,8]. Corticosteroid therapy is associated with lower mortality rate (hazard ratio $=0.24 ; 95 \% \mathrm{CI}=0.07-0.91 ; \mathrm{p}=0.0351$ ) and lower incidence of cardiomyopathy (hazard ratio $=0.38 ; 95 \% \mathrm{CI}=$ $0.16-0.90 ; p=0.0270$ ). However the most frequent adverse effect of corticosteroids is reduction in the patient's height and weight gain. Other adverse effects include cataracts, vertebral fractures, cushingoid facies, acne, hirsutism, arterial hypertension, behaviour disorders, delayed puberty, immunosuppression, and gastrointestinal problems [11-13]. Furthermore the initiation of corticosteroid treatment during early childhood ( $\leq 5$ years) were likely to have higher risk of developing earlier onset cardiomyopathy, fracture and decreased respiratory function, compared to cases who initiated treatment in late childhood or were treatment naïve [17].

According to Guideline Development Subcommittee of the American Academy of Neurology, prednisone should be offered for improving strength and pulmonary function in children with DMD. Prednisone may be offered to improve timed motor function, reduce the need for scoliosis surgery, and delay onset of cardiomyopathy. Prednisone $0.75 \mathrm{mg} / \mathrm{kg} / \mathrm{d}$ has significant benefit in DMD management and should be considered as the optimal prednisone dose $[14,15]$. However it's side effects should be discussed with patients and their families prior to therapy initiation and should be managed proactively [16].

The American College of Rheumatology Task Force osteoporosis guideline recommended calcium and vitamin D 
supplementation for patients whom taking corticosteroids (any dose with an anticipated duration of $\geq 3$ months) in order to maintain total calcium intake $1.000 \mathrm{mg} / \mathrm{d}$ and vitamin D intake $800 \mathrm{IU} / \mathrm{d}$ through dietary sources and supplementation. If the patient develops significant number of adverse effects, reducing the prednisone dosage to 0.3 $\mathrm{mg} / \mathrm{kg} / \mathrm{d}$ may helps, albeit with less efficacy $[17,18]$. In this case, the patient got prednisone therapy for 1 years with dose $0.75 \mathrm{mg} / \mathrm{kg} /$ day, calcium syrup $10 \mathrm{ml} /$ day, Vitamin D 400 IU/day. Routine evaluations were carried out to monitor weight gain as well as signs of cushing syndrome. Currently he has shown improvement in gait and the weakness on both legs became lessen.

\section{Conclusions}

Duchenne Muscular Dystrophy (DMD) is an atypical inherited musculoskeletal disorder with progressive muscular weakness. It is a clinically heterogeneous, severe, irreversible and X-linked recessive disorder occurring 1 in every 4000 live male births, age 3 to 5 years old. Corticosteroid can slow down the decline of muscle function and muscle strength, prolong independent ambulation, improve lung function and delay the onset of cardiomyopathy. It is necessary to provide clear information and perform genetic counseling to patients and their family.

\section{References}

[1] Sinha R, Sarkar S, Khaitan T, Dutta S. (2017). Duchenne muscular dystrophy: Case report and review. J Family Med Prim Care. 6 (3): 654-56.

[2] Jumah AM, Muhaizea AM, Rumayyan AA, Saman AA et al. (2019). Current management of Duchenne muscular dystrophy in the middle east: expert report. Neurodegener Dis Manag. 9 (3): 123-33.

[3] Marden RJ, Freinmark J, Yao Z et al. (2020). Real-world outcomes of long-term prednisone and deflazacort use in patients with Duchenne muscular dystrophy: experience at a single, large care center. J Comp Eff Res. 9 (3): 177-89.

[4] Rathod KG, Dawre RM, Kamble MB et al. (2014). Duchenne Muscular Dystrophy Diagnosed by Dystrophin Gene Deletion Test: A Case Report. Int J Med Res Health. 3 (2): 506-08.

[5] Steinberg H, wagner A. Wilhelm Erb's. (2013). Years in Leipzig (1880-1883) and Their Impact on the History of Neurology. Eur Neurol. 70: 267-75.
[6] Machfoed MH, Besin V, Basuki M, Lasmono SF. (2017). Duchenne muscular dystrophy: overview and future challenges. Aktualn Neurol. 17 (3): 144-49.

[7] Suthar R, Sankhyan N. (2017). Duchenne Muscular Dystrophy: A Practice update. Indian J pediatr. 27: 276-81.

[8] Strehle EM, Straub V. (2015). Recent advances in the management of Duchenne muscular dystrophy. Arch Dis Child. 100: 1173-77.

[9] Wein N, Alfano L, Flanigan KM. (2015). Genetics and emerging treatments for Duchenne and Becker muscular dystrophy. Pediatr Clin North Am. 62: 723-42.

[10] Birnkrant DJ, Busbhy K, Bann CM et al. (2018). Diagnosis and management of Duchenne muscular dystrophy, part 1: diagnosis, and neuromuscular, rehabilitation, endocrine, and gastrointestinal and nutritional management. Lancet Neurol. 17 (3): 251-67.

[11] Joyce NC, Oskarsson B, Jin LW. (2012). Muscle Biopsy Evaluation in Neuromuscular Disorders. Phys Med Rehabil Clin N Am. 23 (3): 609-31.

[12] Schram G, Fournier A, Leduc H et al. (2013). All-cause mortality and cardiovascular outcomes with prophylactic steroid therapy in Duchenne muscular dystrophy. J Am Coll Cardiol. 61: 948-54.

[13] Lamb MM, West NA, Ouyang L et al. (2016). Corticosteroid treatment and growth patterns in ambulatory Males with Duchenne muscular dystrophy. J Pediatr. 173: 207-13.

[14] Beytía ML, Vry J, Kirschner J. (2012). Drug treatment of Duchenne muscular dystrophy: Available evidence and perspectives. Acta Myol. 31: 4-8.

[15] David Gloss, Richard T. Moxley RT, Stephen Ashwal et al. (2016). Corticosteroid treatment of Duchenne muscular dystrophy. Neurology. 86: 465-472.

[16] Guglieri M, Bushby K, McDermott M, Hart KA et al. (2017). Developing Standardized Corticosteroid Treatment for Duchenne Muscular Dystrophy. Contemp Clin Trials. 58: 34-39.

[17] Kim S, Zhu Y, Romitti PA, Fox DJ et al. (2017). Associations between timing of corticosteroid treatment initiation and clinical outcomes in Duchenne muscular dystrophy. Neuromuscular Disorders. 27 (8): 730-37.

[18] Goemans N, vanden HM, Signorovitch J, Swallow E et al. (2016). Individualized Prediction of Changes in 6-Minute Walk Distance for Patients with Duchenne Muscular Dystrophy. Plos One. 13: 1-15. 